\title{
The dielectric studies on sol-gel routed molybdenum oxide thin film
}

\author{
P. Adal Arasu* and R. Victor Williams ${ }^{\dagger}$ \\ Department of Physics, St. Joseph's College, Trichy, India \\ *mr.adalphysics@gmail.com \\ †rvwi@yahoo.com
}

Received 14 February 2017; Revised 29 March 2017; Accepted 1 April 2017; Published 26 April 2017

\begin{abstract}
The influence of temperature on the dielectric properties of sol-gel routed spin-coated molybdenum trioxide $\left(\mathrm{MoO}_{3}\right)$ thin film has been investigated. Prepared films were annealed at temperatures $250^{\circ} \mathrm{C}, 350^{\circ} \mathrm{C}$ and $400^{\circ} \mathrm{C}$. The phase transformation from amorphous to $\alpha$-orthorhombic phase with preferential orientation $\left(\begin{array}{lll}0 & 2 & 2\end{array}\right)$ has been found by XRD for the film annealed above $250^{\circ} \mathrm{C}$. The vibration modes of $\alpha$-orthorhombic $\mathrm{MoO}_{3}$ have been examined by Raman spectrum. The predominant Raman's band of $\alpha$-orthorhombic $\mathrm{MoO}_{3}$ thin film has been found at the frequency range $1000-600 \mathrm{~cm}^{-1}$. Using the UV-Vis spectrum, the band gap of the film is found to be 3.3-3.8 eV. The surface morphology of the $\mathrm{MoO}_{3}$ films has been examined by scanning electron microscope. The AC conductivity measurement of the $\mathrm{MoO}_{3}$ film has been carried out in the frequency range $10-10^{6} \mathrm{~Hz}$. The frequency dependence of the impedance has been plotted in the complex plane. The variation of the capacitance and dielectric constant of $\mathrm{MoO}_{3}$ film with respect to temperature and frequency has been analyzed. Tunability of capacitance and figure of merit of the film are also determined.

Keywords: Sol-gel; dielectric constant; capacitance; tunability; Curie-temperature; figure-of-merit.
\end{abstract}

\section{Introduction}

In modern technological era, the need for new materials with good dielectric behavior has increased. The wide band gap transition metal oxides with notable dielectric behavior have attracted the researchers to fabricate the device with low leakage current level for their operations. The metal oxides exhibit different optoelectronic properties such as electrochromic, photochromic, gas sensing and some of them exhibit high dielectric constant and low dielectric loss that make them a best alternative for conventional $\mathrm{SiO}_{2}$ in the fabrication of DRAM and super capacitors. The molybdenum trioxide $\left(\mathrm{MoO}_{3}\right)$ is one of the transition metal oxides which exhibit good dielectric behavior. Different deposition techniques such as chemical vapor deposition, ${ }^{1}$ electrode deposition, ${ }^{2}$ electron beam deposition, ${ }^{3}$ sputtering ${ }^{4}$ and spray pyrolysis ${ }^{5}$ have been employed to produce $\mathrm{MoO}_{3}$ films. The sol-gel technique has been receiving considerable attention to prepare the high quality films at low cost with simpler deposition procedure. ${ }^{6}$ In this present work, the sol-gel routed spin coating technique has been used for obtaining $\mathrm{MoO}_{3}$ thin films at room temperature with required thickness. Prepared films were annealed at the temperature range 250$400^{\circ} \mathrm{C}$ to convert $\mathrm{MoO}_{3}$ thin film from amorphous to crystalline nature. This work investigates the structural, optical and dielectric properties of the $\mathrm{MoO}_{3}$ thin film. The novelty of the present work is to study the effect of temperature on the dielectric properties of $\mathrm{MoO}_{3}$ thin film in amorphous form.

\section{Materials and Method}

The precursor solution was prepared by mixing $\mathrm{MoO}_{3}$ powder $\left(99.999 \%\right.$, SigmaAldrich) into excess $\mathrm{H}_{2} \mathrm{O}_{2}$ (30\%, Sigma-Aldrich) and the solution was refluxed for $30 \mathrm{~min}$ at $60^{\circ} \mathrm{C}$ in air. The resulting yellow colored solution was cooled to room temperature and left for gellation and during the gellation time, the viscosity and concentration of the solution were adjusted by adding polyethylene glycol (average Mn 200, Sigma-Aldrich) and 2-ethoxyethanol (Sigma-Aldrich). The solution with sufficient viscosity was spin-coated on clean commercially available fluorine-doped tin oxide (FTO) substrates with a sheet resistance of $10 \Omega /$ square. The film was coated as multiple layers to obtain the required thickness. After each layer of coating, the film was dried at $100^{\circ} \mathrm{C}$ for about $5 \mathrm{~min}$. The solution-processed films were annealed at the temperature range of $250-400^{\circ} \mathrm{C}$ for $2 \mathrm{~h}$ by keeping the rate of temperature at $4{ }^{\circ} \mathrm{C}$ per minute. The thickness of the film was measured by stylus profilometer (Mitutoyo, SJ-301). The X-ray diffraction (XRD) for phase identification was performed using XPERT-PRO X-ray diffractometer with $\mathrm{Cu}-\mathrm{K} \alpha(\lambda=0.154 \mathrm{~nm})$ radiation source. Raman spectra were recorded using a micro- Raman spectrometer $(\lambda=514.5 \mathrm{~nm}$, Acton Spectra Pro 2500i, Princeton Instruments, Acton Optics \& Coatings). The surface morphology of $\mathrm{MoO}_{3}$ film was examined by VEGA3 TESCAN scanning electron microscope (SEM). The optical characterization was done by Perkin Elmer Lambda-35 UV-Visible (UV-Vis) spectrometer. The measurements of dielectric properties were carried

This is an Open Access article published by World Scientific Publishing Company. It is distributed under the terms of the Creative Commons Attribution 4.0 (CC-BY) License. Further distribution of this work is permitted, provided the original work is properly cited. 
out using an MIM structure. Capacitance versus voltage, dielectric constant and dielectric loss measurements were carried out using Impedance analyzer (Princeton Applied Research, VersaSTAT MC) and LCRZ meter. Using the impedance data, the Nyquist plot was plotted and the possible equivalent circuit has been identified. Using the temperature variable capacitance measurement set-up, the phase transition temperature of the $\mathrm{MoO}_{3}$ has been determined.

\section{Structural Parameters}

The XRD pattern of $\mathrm{MoO}_{3}$ thin film of thickness of $2.5 \mu \mathrm{m}$ (Fig. 1) exhibits amorphous nature for the film annealed below $250^{\circ} \mathrm{C}$ and crystalline nature for the film annealed at higher temperatures. The films annealed at $350^{\circ} \mathrm{C}$ and $400^{\circ} \mathrm{C}$ exhibit $\alpha$-orthorhombic phase with preferential orientation along (l $\left.\begin{array}{lll}0 & 2 & 0\end{array}\right)$ plane. The peak intensity increases with the

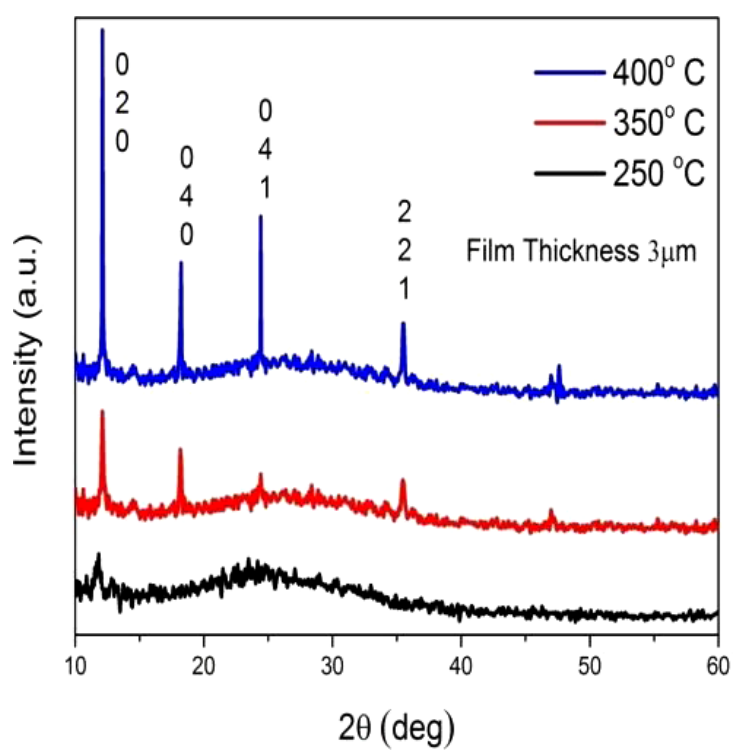

Fig. 1. XRD spectrum of $\mathrm{MoO}_{3}$ thin film. increase of annealing temperature, due to the increase in grain size of the crystal lattice. ${ }^{7}$ The various structural parameters like lattice constants $(a, b, c)$, crystallite size $(D)$, dislocation density $(\delta)$, strain $(\varepsilon)$ and number of crystallites per unit area $(N)$ of $\mathrm{MoO}_{3}$ film are calculated (Table 1). The lattice constants $(a, b, c)$ of $\mathrm{MoO}_{3}$ films annealed at higher temperature were evaluated by using Check Cell software and cross-verified by JCPDS data (JCPDS Card no.: 89-5108). The crystallite size $D$ is evaluated from Scherrer formula:

$$
D=\frac{0.94 \lambda}{\beta \cos \theta},
$$

where $\beta$ is full width at half maximum of XRD peak. The crystallite size increases with the increase of annealing temperature. According to the theory of kinematical scattering, the narrow peak is due to the larger crystallite size and fewer defects present in the crystals. In the present work, the sharp and higher peak of XRD confirm larger crystallite size and improvement in crystalline nature. ${ }^{8}$ The dislocation density is evaluated from the relation: ${ }^{9}$

$$
\delta=\frac{1}{D^{2}}
$$

The decrease of dislocation density with the increase of annealing temperature indicates the reduction of defects due to annealing. The strain $(\varepsilon)$ and number of crystallites per unit area $(N)$ of the film is calculated from the relations: ${ }^{9}$

$$
\begin{gathered}
\varepsilon=\frac{\beta \cos \theta}{4}, \\
N=\frac{t}{D^{3}},
\end{gathered}
$$

where $t$ is thickness of the thin film. The reduction of strain with the increase of annealing temperature reveals the enhancement of crystalline nature. The number of crystal lattice per unit area decreases with the increase of annealing

\begin{tabular}{|c|c|c|c|c|c|c|}
\hline $\begin{array}{l}\text { Annealing } \\
\text { temperature }\left({ }^{\circ} \mathrm{C}\right)\end{array}$ & Structure/Lattice & $\begin{array}{c}\text { Lattice } \\
\text { constant }\left(\mathrm{A}^{\circ}\right)\end{array}$ & $\begin{array}{c}\text { Crystallite } \\
\text { size }(D)(\mathrm{nm})\end{array}$ & $\begin{array}{c}\text { Dislocation } \\
\text { density }(\delta) \times 10^{15} \\
\left(\text { lines } / \mathrm{m}^{2}\right)\end{array}$ & $\begin{array}{l}\text { Strain }(\varepsilon) \times 10^{-2} \\
\quad\left(\text { line }^{-1} \mathrm{~m}^{-4}\right)\end{array}$ & $\begin{array}{c}\text { Number of crystallites } \\
\text { per unit area } \\
(N) \times\left(10^{16} / \mathrm{m}^{2}\right)\end{array}$ \\
\hline 250 & Amorphous & - & - & - & - & - \\
\hline 350 & Orthorhombic/primitive & $\begin{array}{c}a=3.7 \\
b=13.9 \\
c=3.3\end{array}$ & 51.78 & 3.55 & 6.56 & 11.37 \\
\hline 400 & Orthorhombic/primitive & $\begin{array}{c}a=4.3 \\
b=13.8 \\
c=3.5\end{array}$ & 63.87 & 2.26 & 6.32 & 9.41 \\
\hline
\end{tabular}
temperatures due to the increase of crystallite size. The surface morphology of the film has been investigated by SEM

Table 1. Structural properties.

Note: Lattice constant $(a, b, c)$, crystallite size $(D)$, strain $(\varepsilon)$, dislocation density $(\delta)$, number of crystallites per unit area $(N)$. 


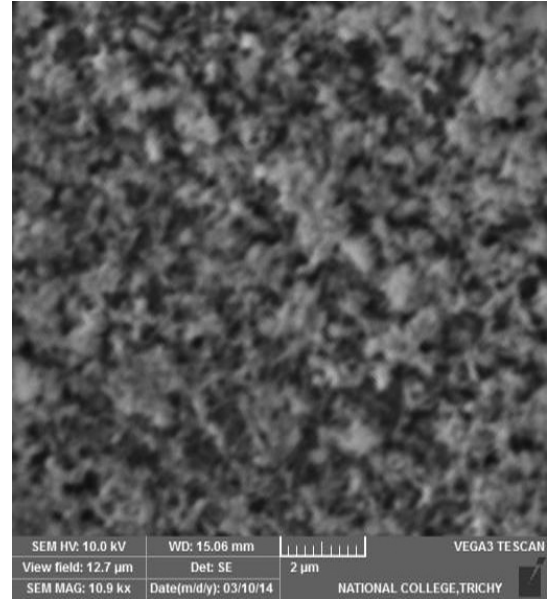

(a)

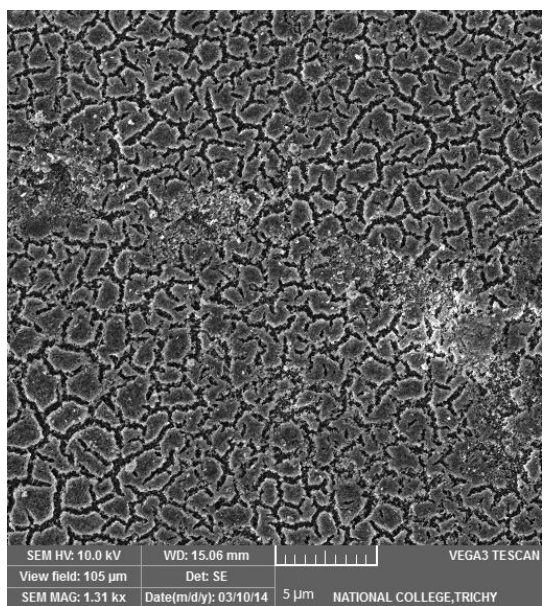

(c)

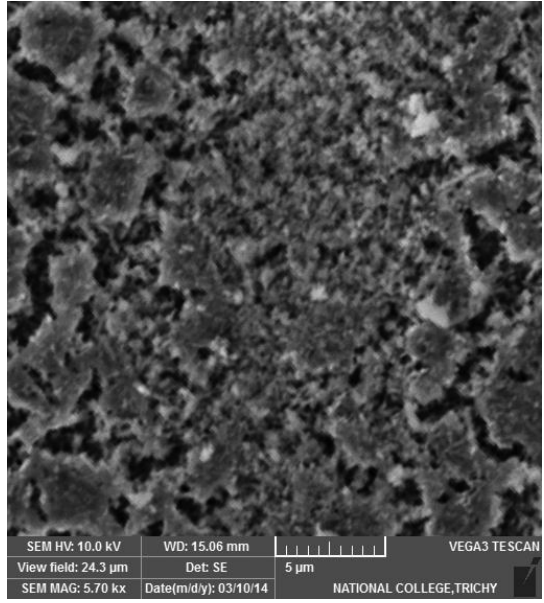

(b)

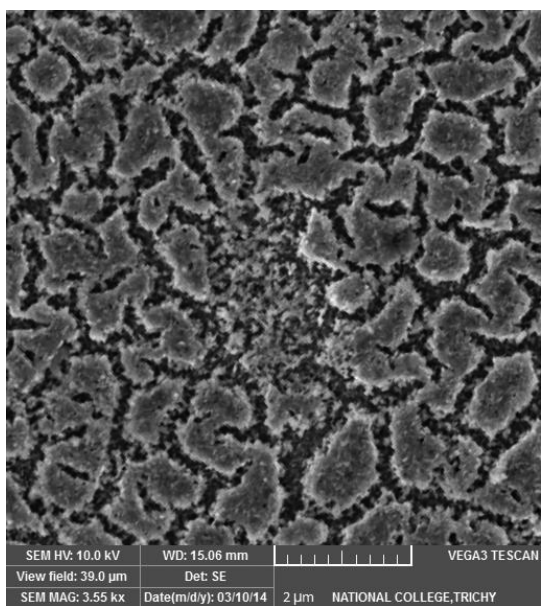

(d)

Fig. 2. (a) SEM images of $\mathrm{MoO}_{3}$ thin film before annealing, (b) SEM images of $\mathrm{MoO}_{3}$ thin film before annealing, (c) SEM images of MoO thin film annealed at $400^{\circ} \mathrm{C}$ and (d) SEM images of $\mathrm{MoO}_{3}$ thin film annealed at $400^{\circ} \mathrm{C}$.

(Fig. 2). It shows that the film is homogeneous and the grain boundaries are evenly distributed though out the sample and it also indicates the heat treatment increase the size of grain boundaries (Figs. 2(c) and 2(d)).

\subsection{Micro Raman studies}

A typical Raman spectrum of the $\mathrm{MoO}_{3}$ thin film is shown in (Fig. 3). The vibration modes appearing in the frequency ranges of $1000-600 \mathrm{~cm}^{-1}$ and $600-200 \mathrm{~cm}^{-1}$ correspond to the stretching and deformation modes, respectively. The narrow band at $994 \mathrm{~cm}^{-1}$ is assignable to the antisymmetric $\nu_{\mathrm{as}}(\mathrm{Mo}=\mathrm{O}) A_{g}$ stretching, in which the strong band at $830 \mathrm{~cm}^{-1}$ represents the symmetric $\nu_{\mathrm{s}}\left(\mathrm{Mo}-\mathrm{O}_{3}-\mathrm{Mo}\right)$ $\mathrm{A}_{g}$ stretching. The weak and broad bands at $666 \mathrm{~cm}^{-1}$ and $470 \mathrm{~cm}^{-1}$ are ascribable to the anti-symmetric $\nu_{\mathrm{as}}\left(\mathrm{Mo}-\mathrm{O}_{2}-\mathrm{Mo}\right)$

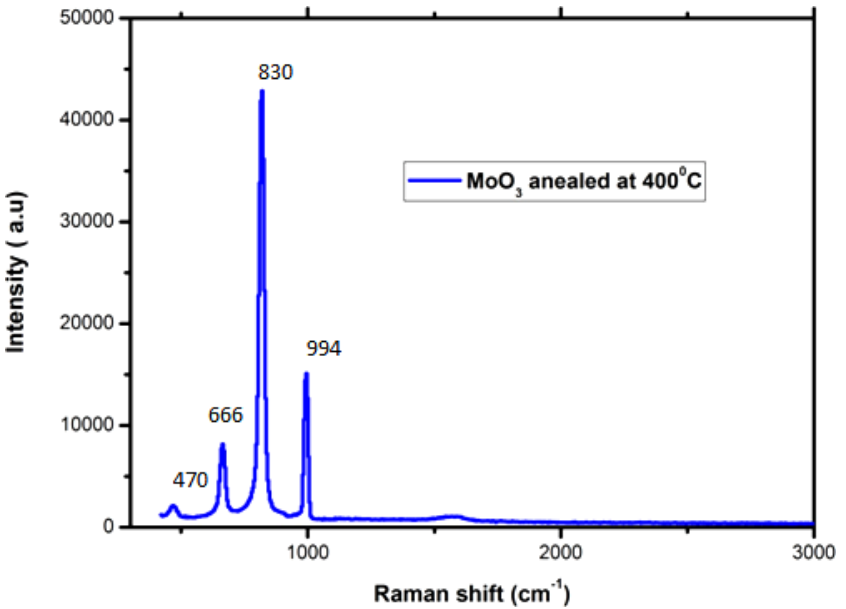

Fig. 3. Raman spectrum of $\mathrm{MoO}_{3}$ thin film. 
$\mathrm{B}_{2 g}$ stretching and bending, respectively. The bands at $377 \mathrm{~cm}^{-1}$ and $364 \mathrm{~cm}^{-1}$ correspond to the $\delta\left(\mathrm{O}_{2}=\right.$ $\left.\mathrm{Mo}=\mathrm{O}_{2}\right) \mathrm{B}_{1 \mathrm{~g}}$ scissor. The Raman band at $830 \mathrm{~cm}^{-1}$ reveals the formation of $\alpha$ orthorhombic phase in $\mathrm{MoO}_{3}$ film at higher annealing temperature. ${ }^{10}$

\section{Optical Properties}

The optical transmission spectra of $\mathrm{MoO}_{3}$ films annealed at various temperatures exhibit good transparency at $575 \mathrm{~nm}$ (Fig. 4). The films annealed at $250^{\circ} \mathrm{C}$ manifests clearly the maximum transparency of $85 \%$. The film annealed at $400^{\circ} \mathrm{C}$ exhibits only $65 \%$ of transparency at $575 \mathrm{~nm}$ due to the free carrier absorption and scattering of light by formation of micro crystallites. ${ }^{11}$ The optical behavior of the film annealed at $350^{\circ} \mathrm{C}$ is different from the others indicating the phase transformation around $300^{\circ} \mathrm{C}$ which causes more absorption by charge carriers. The higher transmittance in the higher wavelength region indicates the decrement in optical band gap $\left(E_{g}\right)$ with the increase of the annealing temperatures. From the transmission spectrum, the absorption coefficient $(\alpha)$ is determined by the relation. ${ }^{12}$

$$
\alpha=\frac{1}{t} \ln T,
$$

where $t$ is thickness of the film and $T$ is transmittance. The band gap of the film is determined from the relation ${ }^{13}$

$$
(\alpha h \nu)^{\frac{1}{n}}=A\left(h v-E_{g}\right) .
$$

where $A$ is the constant, $E_{g}$ optical band gap energy of the material and $n=1 / 2,2,3 / 2$ and 3 corresponding to the allowed direct, allowed indirect, forbidden direct and

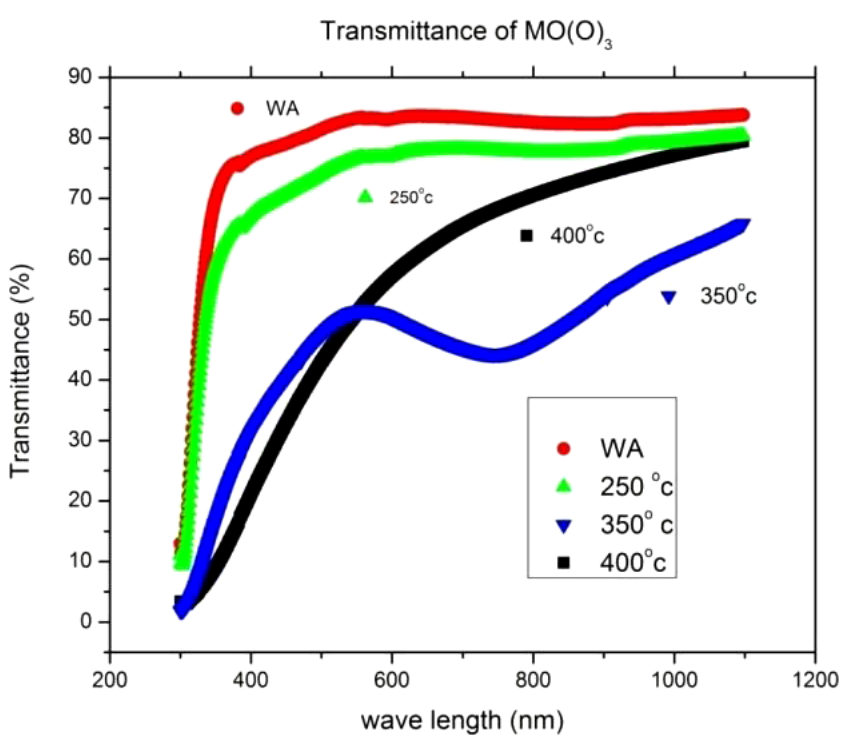

Fig. 4. UV transmittance spectrum of $\mathrm{MoO}_{3}$ thin film.

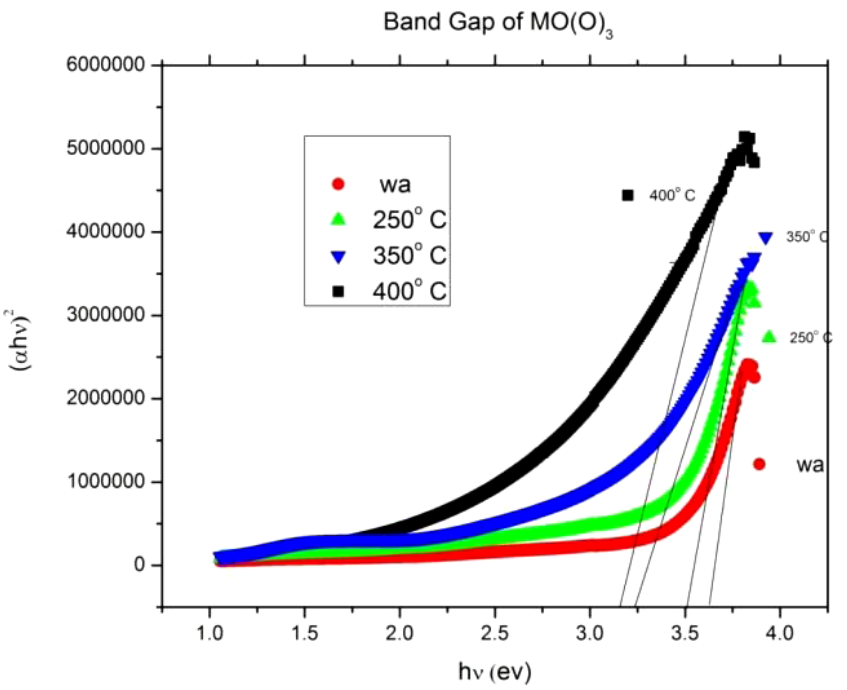

Fig. 5. The plot of $(\alpha h v)^{3}$ as a function of $h v$.

forbidden indirect transitions, respectively. The optical band gap depends upon the absorption coefficient $(\alpha)$. The $\mathrm{MoO}_{3}$ is found to be direct band gap material $(n=1 / 2)$. The extrapolation of linear portion $(\alpha=0)$ gives the optical band gap energy of the film. Figure 5 shows the plot of $(\alpha h v)^{2}$ versus $h v$ for $\mathrm{MoO}_{3}$ at different annealing temperatures. It reveals that the optical band gap of the $\mathrm{MoO}_{3}$ film decreases with the increase of the annealing temperature that might be due to the formation of oxygen ion vacancies and the improvement of crystallinity in the film. ${ }^{11}$ This presumption is consistent with our XRD finding. The optical band gap value

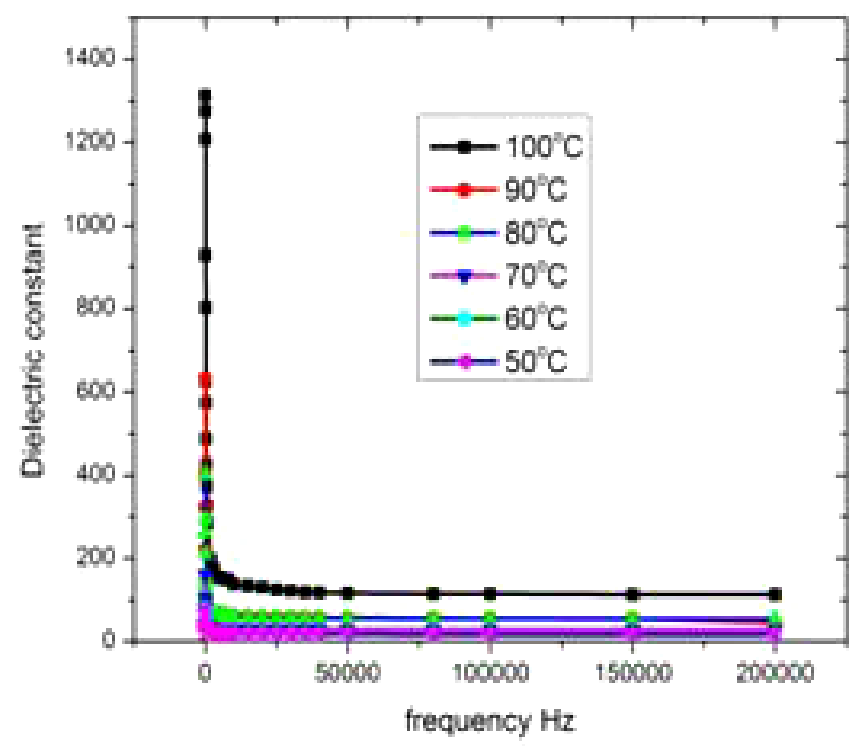

Fig. 6. The plot of dielectric constant as a function of frequency and temperature. 
of $\mathrm{MoO}_{3}$ film at $250^{\circ} \mathrm{C}, 350^{\circ} \mathrm{C}$ and $400^{\circ} \mathrm{C}$ are $3.8,3.5$ and $3.3 \mathrm{eV}$, respectively.

\section{Dielectric Properties}

The value of dielectric constant decreases with the increase of frequency (Fig. 6). It might be due to the alignment of permanent dipoles along with the direction of electric field at lower frequency and it contributes to the total polarization of the dielectric material. On the other hand, at higher frequency as the field rapidly vary, the dipole can no longer follow the field. ${ }^{14}$ Hence, their contribution to the

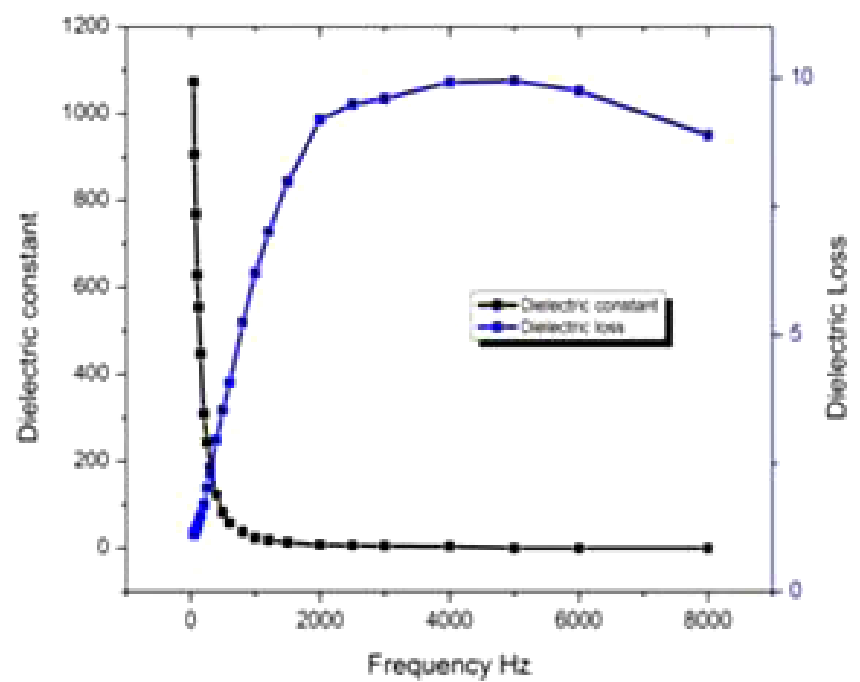

Fig. 7. The plot of dielectric constant and dielectric loss as a function of frequency.

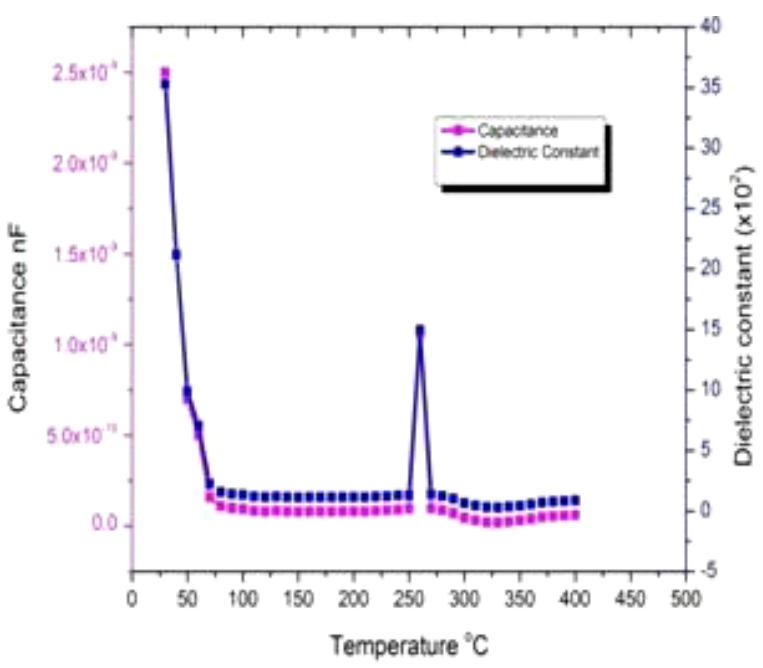

(a) polarization becomes negligible and it leads to increment in the dielectric loss and decrement in dielectric constant (Fig. 7). The increment in the dielectric constant with the increase of temperature is attributed to the increase of grain size and more electrical polarizability of the material. ${ }^{14}$ (Fig. 6).

Figure 8(a) and 8(b) show that the variation of the capacitance and dielectric constant of the $\mathrm{MoO}_{3}$ thin film with respect to temperature, it fits very well with Curie-Wiess law. At $260^{\circ} \mathrm{C}$, the capacitance and dielectric constant reach a maximum value which indicates the phase transition in the material. ${ }^{15}$ This temperature is the transition temperature or Curie temperature $\left(T_{\mathrm{c}}\right)$, beyond which the material behaves as paraelectric. The above fact is supported by the XRD data. The XRD spectrum of the sample annealed above $250^{\circ} \mathrm{C}$ reveals the crystalline nature of $\mathrm{MoO}_{3}$ thin film. The measurement of capacitance with respect to DC electric field was carried out at room temperature for $1 \mathrm{KHz}$ and $100 \mathrm{KHz}$ (Fig. 9). The tunability and figure of merit (FoM) were determined from the following relations: ${ }^{16}$

$$
\begin{gathered}
\text { Tunability }=\frac{C_{\max }-C_{\min }}{C_{\min }} \times 100, \\
\text { FoM } \frac{\% \text { Tunability }}{\% \text { dielectricloss }},
\end{gathered}
$$

where $C_{\max }$ is the capacitance value for zero bias field. $C_{\min }$ denotes the capacitance of applied field. The applied field is in the order of $10^{6} \mathrm{~V} / \mathrm{m}$. The tunability and FOM of the $\mathrm{MoO}_{3}$ film increases with the increase of applied potential (Fig. 10). The tunability of the dielectric properties of the material might be attributed to internal stress among the grains. ${ }^{17}$

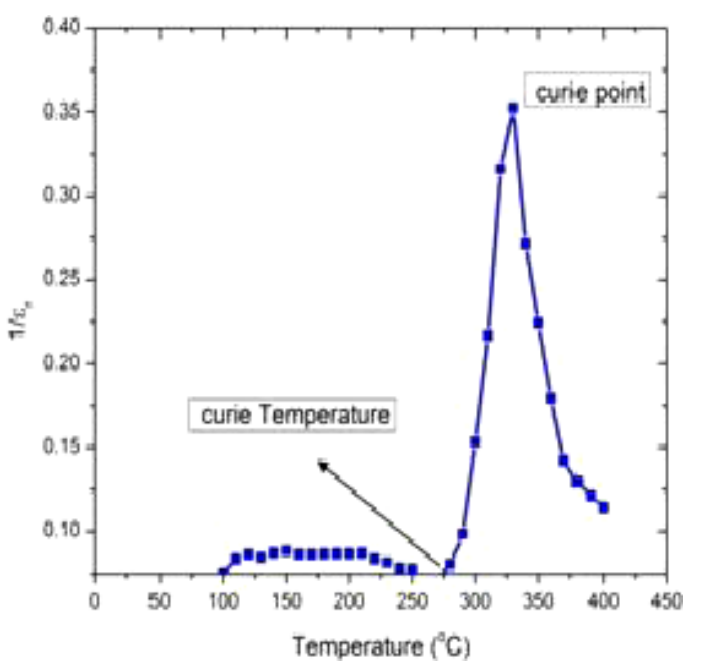

(b)

Fig. 8. (a) The plot of capacitance and dielectric constant as a function of temperature, (b) The plot of $1 / \varepsilon_{r}$ as a function of temperature. 


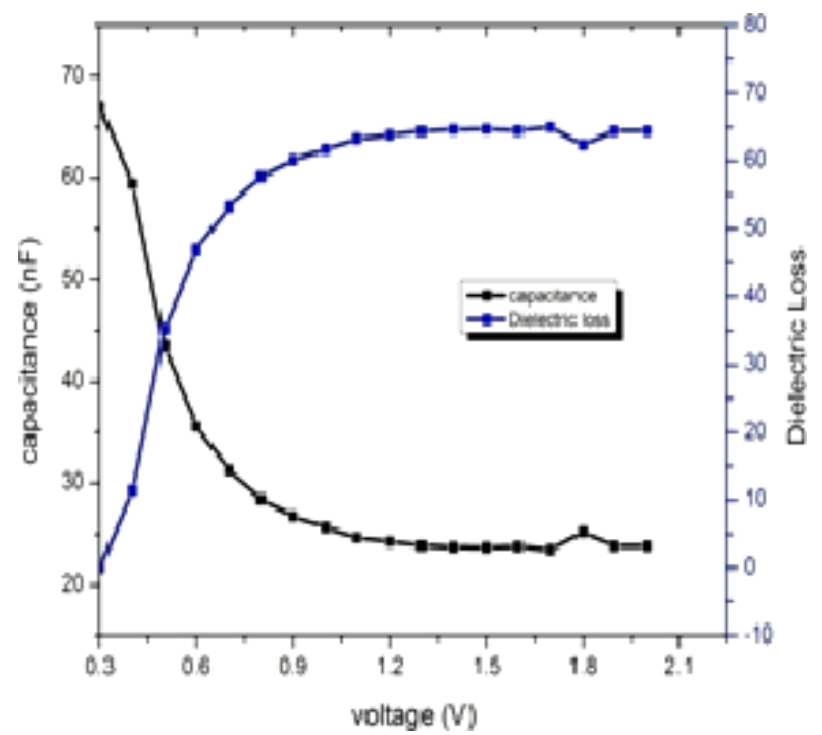

Fig. 9. The plot of capacitance and dielectric loss as the function of voltage.

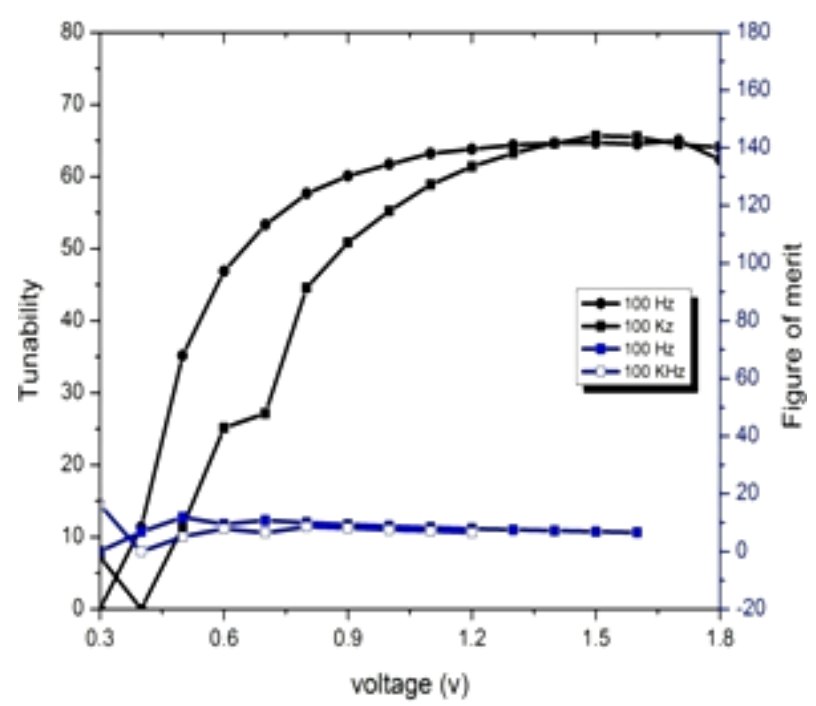

Fig. 10. The plot of tunability and FoM as the function of voltage.

\subsection{The impedance studies}

The impedance spectroscopy studies on $\mathrm{MoO}_{3}$ thin film were carried out by using the complex impedance spectra. It can be fitted with a simple electrical model $R_{b}\left(R_{\mathrm{gb}} \mathrm{C}_{\mathrm{gb}}\right)$, where $R_{b}$ and $R_{\mathrm{gb}}$ are bulk and grain boundary resistance, respectively, and $C_{\mathrm{gb}}$ is the capacitance across the grain boundary. The impedance of the film with resistance $R_{\mathrm{gb}}$ in parallel with a capacitance $C_{\mathrm{gb}}$ is given by the expression. ${ }^{18}$

$$
z_{\mathrm{gb}}=\frac{1}{R_{\mathrm{gb}}^{-1}+j \omega C_{\mathrm{gb}}},
$$

where $\omega=2 \pi f$.

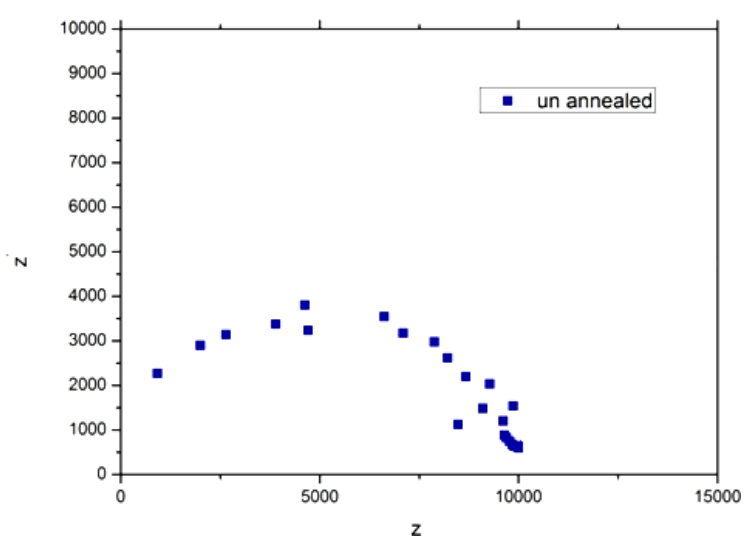

(a)

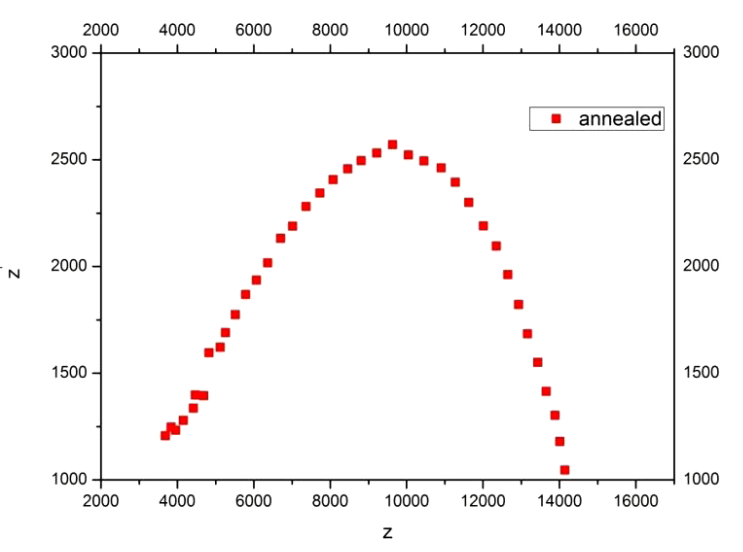

(b)

Fig. 11. (a) Nyquist plot of unannealed $\mathrm{MoO}_{3}$ thin film, (b) Nyquist plot of annealed $\mathrm{MoO}_{3}$ thin film.

The above equation can be expressed as

$$
\left(\frac{\left(Z_{\mathrm{gb}}^{\prime}-R_{\mathrm{gb}}\right)}{2}\right)^{2}+Z_{\mathrm{gb}}^{\prime \prime}=\left(\frac{R_{\mathrm{gb}}}{2}\right)^{2},
$$

where $Z_{\mathrm{gb}}^{\prime}$ and $Z_{\mathrm{gb}}^{\prime \prime}$ are the real and imaginary components of the $Z_{\mathrm{gb}}$, respectively. The corresponding plot of the real $Z_{\mathrm{gb}}$ against the imaginary component of $Z_{\mathrm{gb}}$ (Fig. 11(a) Nyquist plot) is a semicircle of radius $R_{\mathrm{gb}} / 2$. The $R_{\mathrm{gb}}$ and $R_{b}$ values were derived from the intercept of the semicircle with real axis at low and high frequencies, respectively. In the midfrequency region, linear progress of the diffusion characteristic of $\mathrm{MoO}_{3}$ is observed. At the low frequency region, the capacitive behavior is observed which reveals the characteristic response of blocked diffusion. ${ }^{19}$

The impedance response of the grain dominates at high frequency and resistance of the grain $R_{g}$ is deduced from the left intercept to real axis. The right intercept of the semicircle to real axis $Z^{\prime}$ at low frequency indicates the sum of resistance of grain $R_{g}$ and grain boundaries $R_{\mathrm{gb}}$. Figure 11(b) shows that the resistance of the bulk and grain boundaries increases due to the increase of grain size by heat treatment. 


\section{Conclusion}

The effect of temperature on the dielectric properties of solgel routed spin-coated $\mathrm{MoO}_{3}$ thin film has been investigated. The phase transformation from amorphous to $\alpha$-orthorhombic phase has been found by XRD for the film annealed at higher temperature. The Raman spectrum reveals that the predominant Raman's band of $\alpha$-orthorhombic $\mathrm{MoO}_{3}$ thin film has been found at the frequency ranges of 1000 $600 \mathrm{~cm}^{-1}$. The band gap of the film is found to be $3.3-3.8 \mathrm{eV}$. SEM image shows that the film is homogeneous and the grain boundaries are evenly distributed throughout the sample. The impedance plot in the complex plane reveals semicircular arc. The system could be represented by an equivalent circuit of parallel resistance-capacitance combination. The variation of the capacitance and dielectric constant of $\mathrm{MoO}_{3}$ film with respect to temperature and frequency has been analyzed. Tunability and FoM of the film are also determined. The obtained data can be utilized for the fabrication of dielectric devices.

\section{References}

${ }^{1}$ H. R. An, H. J. Ahn and J. W. Park, High-quality, conductive, and transparent $\mathrm{Ga}$-doped $\mathrm{ZnO}$ films grown by atmosphericpressure chemical-vapor deposition, Ceram. Int. 41, 2253 (2015), doi: 10.1016/j.ceramint.2014.10.028.

${ }^{2}$ R. S. Patil, M. D. Uplane and P. S. Patil, Structural and optical properties of electrodeposited molybdenum oxide thin films, Appl. Surf. Sci. 252, 8050 (2006), doi: 10.1016/j.apsusc. 2005.10.016.

${ }^{3}$ J. Tamaki, C. Naruo, Y. Yamamoto and M. Matsuoka, Sensing properties to dilute chlorine gas of indium oxide based thin film sensors prepared by electron beam evaporation, Sens. Actuators B, Chem. 83, 190 (2002), doi: 10.1016/S0925-4005(01) 01039-5.

${ }^{4}$ S.-W. Fu, H.-J. Chen, H.-T. Wu, K.-T. Hung and C.-F. Shih, Electrical and optical properties of $\mathrm{Al}: \mathrm{ZnO}$ films prepared by ionbeam assisted sputtering, Ceram. Int. 42, 2626 (2016), doi: 10.1016/j.ceramint.2015.10.067.

${ }^{5}$ K. S. Hwang, Y. S. Jeon, S. Hwangbo and J. T. Kim, Praseodymium-doped calcium stannates phosphor coatings prepared by electrostatic spray deposition, Ceram. Int. 39, 8555 (2013), doi: 10.1016/j.ceramint.2013.04.002.

${ }^{6}$ Q. G. Chi, Y. Cui, Y. Chen, J. Q. Lin, X. Wang and Q. Q. Lei, Low temperature preparation and electric properties of highly (100)-oriented ( $\mathrm{Na} 0.85 \mathrm{~K} 0.15) 0.5 \mathrm{Bi} 0.5 \mathrm{TiO} 3$ thin films prepared by a sol-gel route, Ceram. Int. 42, 2497 (2016), doi: 10.1016/j. ceramint.2015.10.050.
${ }^{7}$ S. A. Vanalakar et al., Effect of post-annealing atmosphere on the grain-size and surface morphological properties of pulsed laser deposited CZTS thin films, Ceram. Int. 4015097 (2014), doi: 10.1016/j.ceramint.2014.06.121.

${ }^{8} \mathrm{D}$. Fang, P. Yao and H. Li, Influence of annealing temperature on the structural and optical properties of $\mathrm{Mg}-\mathrm{Al}$ co-doped $\mathrm{ZnO}$ thin films prepared via sol-gel method, Ceram. Int. 40, 5873 (2014), doi: 10.1016/j.ceramint.2013.11.030.

${ }^{9}$ P. A. Arasu and R. V. Williams, Effect of annealing temperature on structural and optical parameters of sol-gel routed molybdenum oxide thin film, Surf. Rev. Lett. 22, 1550054 (2015), doi: 10.1142/ S0218625X15500547.

${ }^{10}$ R. Boughalmi, A. Boukhachem, M. Kahlaoui, H. Maghraoui and M. Amlouk, Physical investigations on $\mathrm{Sb}_{2} \mathrm{~S}_{3}$ sprayed thin film for optoelectronic applications, Mater. Sci. Semicond. Process. 26, 593 (2014), doi: 10.1016/j.mssp.2014.05.059.

${ }^{11}$ K. S. Usha, R. Sivakumar and C. Sanjeeviraja, Optical constants and dispersion energy parameters of $\mathrm{NiO}$ thin films prepared by radio frequency magnetron sputtering technique, J. Appl. Phys. 114, 123501 (2013), doi: 10.1063/1.4821966.

${ }^{12}$ S. P. Anthony, J. I. Lee and J. K. Kim, Tuning optical band gap of vertically aligned $\mathrm{ZnO}$ nanowire arrays grown by homoepitaxial electrodeposition, Appl. Phys. Lett. 90, 19 (2007), doi: 10.1063/1.2711419.

${ }^{13}$ B. P. Kafle, S. Acharya, S. Thapa and S. Poudel, Structural and optical properties of fe-doped Zno transparent thin films, Ceram. Int. 42, 1133 (2016), doi: 10.1016/j.ceramint.2015.09.042.

${ }^{14} \mathrm{P}$. Kumar, Dielectric relaxation in complex perovskite oxide $\mathrm{Sr}$ (Gd0.5Nb0.5)O3, Mater. Sci. Appl. 3, 369 (2012), doi: 10.4236/ msa.2012.36053.

${ }^{15} \mathrm{~L}$. Shi et al., Piezoelectric properties of $\mathrm{Fe}_{2} \mathrm{O}_{3}$ doped $\mathrm{BiYbO}{ }_{3}-\mathrm{Pb}$ (Zr,Ti) $\mathrm{O}_{3}$ high Curie temperature ceramics, Ceram. Int. 40, 11485 (2014), doi: 10.1016/j.ceramint.2013.10.043.

${ }^{16} \mathrm{~V}$. Eswaramoorthi and R. V. Williams, Effect of thickness on microstructure, dielectric and opticl properties of single layer $\mathrm{Ba}_{0.6} \mathrm{Sr}_{0.4} \mathrm{TiO}_{3}$ thin film, Surf. Rev. Lett. 21, 1450020 (2014), doi: 10.1142/S0218625X14500206.

${ }^{17}$ V. Eswaramoorthi and R. V. Williams, Structural, optical and electrical properties of sol-gel derived (Ba0.6Sr0.4) (NixTi1_x) $\mathrm{O}_{3}$ thin films, Ceram. Int. 41, 2434 (2015), doi: 10.1016/j.ceramint.2014.10.057.

${ }^{18} \mathrm{M}$. A. Ponce et al., Impedance spectroscopy analysis of $\mathrm{TiO} 2$ thin film gas sensors obtained from water-based anatase colloids, Sens. Actuators B, Chem. 139, 447 (2009), doi: 10.1016/j. snb.2009.03.066.

${ }^{19}$ R. Mariappan, V. Ponnuswamy, P. Suresh, N. Ashok, P. Jayamurugan and A. Chandra Bose, Influence of film thickness on the properties of sprayed $\mathrm{ZnO}$ thin films for gas sensor applications, Superlattices Microstruct. 71, 238 (2014), doi: 10.1016/j. spmi.2014.03.029. 